\title{
Teoria da contingência no contexto capacitante da biblioteca multinível
}

\author{
Jobson Louis Santos de Almeida ${ }^{I}$ \\ http://orcid.org/0000-0003-4146-5747 \\ Joana Coeli Ribeiro Garcia ${ }^{I I}$ \\ http://orcid.org/0000-0001-6423-9422
}

Gustavo Henrique de Araújo Freire ${ }^{I I I}$

http://orcid.org/0000-0002-5540-4630

I Universidade Federal da Paraíba, PB, Brasil.

Docente no Departamento de Ciência da Informação.

Dourando em Ciência da Informação.

${ }^{I I}$ Universidade Federal da Paraíba, PB, Brasil.

Docente no Departamento de Ciência da Informação

e no Programa de Pós-Graduação em Ciência da Informação.

Doutora em Ciência da Informação.

III Universidade Federal do Rio de Janeiro, RJ, Brasil.

Professor Associado I da Universidade Federal do Rio de Janeiro.

Doutor em Ciência da Informação.

\section{http://dx.doi.org/10.1590/1981-5344/3875}

Objetiva refletir sobre a aplicação da abordagem contingencial no contexto capacitante da biblioteca multinível. Metodologicamente, consiste em um estudo teórico reflexivo, de natureza qualitativa, que fez uso da técnica bibliográfica. A discussão abrange a perspectiva conceitual do Ministério da Educação acerca do Plano de Contingência, os desafios para a biblioteca multinível brasileira quanto a elaboração deste a partir da exigência dos instrumentos de avaliação dos cursos superiores do governo brasileiro e a importância de um contexto favorável a criação de conhecimento para o atendimento das demandas emergenciais. $O$ resultado do estudo 
evidencia a necessidade de um contexto capacitante, conforme a perspectiva conceitual de Krogh, Ichijo e Nonaka, que oportunize não somente a criação de conhecimento, mas também o desenvolvimento de competência em informação necessária para a elaboração, execução e avaliação do Plano de Contingência.

Palavras-chave:Teoria da Contingência, Criação de conhecimento, Competência em informação, Biblioteca Multinível, Ciência da Informação

\section{Contingency theory in the context capacitant of the multilevel library}

It aims to reflect on the application of the contingency approach in the enabling context of the multilevel library. Methodologically, it consists of a reflective theoretical study, of a qualitative nature, that made use of the bibliographical technique. The discussion covers the conceptual perspective of the Ministry of Education about the Contingency Plan, the challenges for the Brazilian multilevel library regarding the elaboration of this one based on the demand of the instruments of evaluation of the higher courses of the Brazilian government and the importance of a context favorable to the creation knowledge to meet the emergency demands. The result of the study evidences the need for an enabling context, according to the conceptual perspective of Krogh, Ichijo and Nonaka, that allows not only the creation of knowledge, but also the development of competence in information necessary for the elaboration, execution and evaluation of the Plan of Contingency.

Keywords:Contingency Theory, Creation of knowledge, Information Literacy, Multilevel Library, Information Science.

Recebido em 26.02.2019. Aceito em 31.03.2020 


\section{Introdução}

Nos estudos recentes que versam sobre tipologia e identidade organizacional de bibliotecas, há a proposta inédita de adoção da terminologia "biblioteca multinível" para as bibliotecas das instituições da Rede Federal de Educação Profissional, Científica e Tecnológica no Brasil,que em sua maioria são bibliotecas de Institutos Federais. Tal termo foi idealizado pioneiramente por Moutinho (2014, p. 71) no campo da Educação, ao discorrer que:

Após a criação da lei 11.892/2008, essas bibliotecas se tornaram escolares, universitárias e especializadas, pois passou a ter demandas dos níveis: ensino médio, técnico, graduações e pósgraduações tecnológicas, programas como PIBIC, PARFOR, Mulheres Mil, Certific, entre outros. Com essa grande quantidade de cursos e modalidades, surge uma instituição ímpar em nosso país, uma instituição multinível e multimodal, sendo necessária uma classificação para o tipo de biblioteca que essa instituição possui, a que classificaremos como bibliotecas multiníveis, pois atende a usuários de vários níveis de ensino.

Em seguida, o termo "biblioteca multinível" foi estudado e disseminado no campo da Biblioteconomia e da Ciência da Informação por Almeida (2015, p. 45), para o qual a biblioteca é percebida como

uma organização que atende às necessidades de um público de diferentes níveis de processos formativos (nível médio, técnico e superior) e, consequentemente, diferentes níveis de necessidades e competências informacionais.

Tomando por base os estudos realizados até o presente momento, consideramos que a terminologia proposta apresenta-se coerente, inovadora e suficientemente abrangente, atendendo aos pressupostos teórico-metodológicos presentes na literatura científica nacional e internacional.

A biblioteca multinível completou dez anos de existência no Brasil em 2018, com presença em centenas de instituições federais de ensino no Brasil. Especificamente no campo da Ciência da Informação, destacam-se os estudos teóricos realizados por Almeida e Freire (2018), com enfoque na biblioteca como organização aprendente e no desenvolvimento de competência em informação. Dentre muitos desafios, a partir de 2018, o Ministério da Educação atualizou os instrumentos de avaliação dos cursos superiores, com destaque para exigência do Plano de Contingência a ser incorporado pelas bibliotecas. 
O presente trabalho é fruto das discussões realizadas na disciplina "Ética, Gestão e Políticas de Informação", em nível de Doutorado, no Programa de Pós-Graduação em Ciência da Informação da Universidade Federal da Paraíba (UFPB). Objetiva refletir sobre a aplicação teórica da abordagem contingencial no contexto capacitante da biblioteca multinível. A discussão abrange a perspectiva conceitual do Ministério da Educação do Brasil acerca do Plano de Contingência, os desafios para a biblioteca multinível brasileira quanto a elaboração deste a partir da exigência dos novos instrumentos de avaliação dos cursos superiores do governo brasileiro, e da importância de um contexto favorável à criação de conhecimento para o devido atendimento das demandas emergenciais.

Metodologicamente, consiste em um estudo teórico reflexivo, de natureza qualitativa, que fez uso da técnica de pesquisa bibliográfica. 0 ponto de partida da reflexão é a Teoria da Contingência. Buscamos entender, a princípio, em que consiste essa teoria administrativa e as concepções existentes sobre contingência e Plano de Contingência. Em seguida, nosso percurso reflexivo se dará pelo contexto capacitante da biblioteca multinível, em que também apresentaremos a definição e as características desse novo tipo de unidade de informação. Será realizada uma interseção teórica entre a abordagem de Krogh, Ichijo e Nonaka (2001) sobre solicitude organizacional e a abordagem de Almeida e Freire (2018) sobre o desenvolvimento de competência em informação.

Por fim, discutiremos sobre a aplicação teórica da abordagem contingencial na biblioteca multinível frente as demandas e os desafios contemporâneos.

\section{Contingência: teoria, estratégia, plano e perspectivas conceituais}

A Teoria da Contingência foi uma das teorias administrativas mais influentes da segunda metade do século $X X$ e continua sendo no século XXI. É dela que vem a compreensão de que não há nada absoluto nas organizações ou na teoria administrativa, pois tudo é relativo. De acordo com Chiavenato (2014), a teoria parte do princípio de que não existe um modelo ideal para atender a todos os tipos de organizações e seus panoramas, pois existe apenas uma única certeza, a saber: a constante necessidade de mudanças em todos os aspectos, sejam eles internos ou externos. Ela nos possibilita afirmar, portanto, que não podemos garantir que um aspecto (técnica, estratégia, processo organizacional, estrutura, tecnologia, etc.) de uma organização possa ser aplicado a outras organizações da mesma forma, pois nelas, sejam públicas ou privadas, os ambientes e os fatores (internos e externos, individuais e coletivos) são diferentes. 
Para Beuren e Fiorentin (2014), a Teoria da Contingência enfatiza como os fatores contingentes (cultura, tamanho, ambiente, tarefas, tecnologia, métodos) afetam o funcionamento das organizações. Essa teoria procura compreender e explicar como as organizações funcionam em diferentes condições, que variam de acordo com o contexto (temporal e ambiental) em que estão inseridas. As mudanças que ocorrem no ambiente organizacional, social e no mercado competitivo, devem ser continuamente monitoradas para garantia da competitividade e da qualidade da organização.

A abordagem contingencial é funcionalista e tende a auxiliar os processos decisórios e contribuir para o sucesso da estratégia organizacional. Não apenas é relevante a utilização da teoria, mas também a evidenciação da mesma no ambiente de trabalho. A estratégia contingencial de toda e qualquer unidade de informação deverá estar explicitada, portanto, em documento, denominado: Plano de Contingência.

Não se trata da única abordagem em gestão organizacional que contempla esses mesmos fundamentos. Bastante valorizada na área da Biblioteconomia, a perspectiva sistêmica, de acordo com García-Reyes (2007), considera as unidades de informação como sistemas abertos, reunindo elementos com um propósito em comum, que se relacionam e interagem uns com os outros e com o seu ambiente externo. Para se adaptar a este, elas desenvolvem, portanto, mecanismos de controle e feedback. Longo (2007, p. 44, grifo nosso) ressalta a importância do pensamento sistêmico por parte do profissional da informação para, entre outras coisas, mobilizar pessoas, resolver problemas e crises, ao afirmar que:

A relação entre o crescimento da informação disponível e o crescimento da complexa tecnologia para tratar essa informação gera a necessidade de mudar e ampliar as habilidades essenciais do profissional em questão. Fundamental, entretanto, é a conscientização, cada vez maior, da nova mentalidade emergente. Precisamos de profissionais que possuam visão de futuro, foco estratégico e características de liderança eficaz, além da utilização de todo o seu potencial criativo. O novo profissional da informação precisa ter condições de reexaminar constantemente suas premissas e crenças a partir da capacidade de pensar de forma sistêmica, traduzida pela capacidade de ver conexões entre eventos, assuntos e detalhes e de pensar no todo e não nas partes, de forma isolada. Além disso, o profissional precisa estar disposto a assumir riscos, ser flexível e capaz de sonhar e compartilhar as esperanças que mobilizem as pessoas. O profissional da informação eficaz é aquele que se utiliza de uma abordagem sistemática para analisar e solucionar problemas, constrói uma infraestrutura orgânica baseada 
em estratégias sólidas, entende as necessidades singulares dos clientes e resolve falhas de comunicação. O profissional da informação precisa exercer sua liderança para resolver crises e/ou capitalizar oportunidades, aplicando metodologias coerentes e estruturadas no desenvolvimento dos sistemas de informação. Precisa conhecer não apenas uma área ou setor, mas toda a organização para a qual trabalha, podendo assim fazer frente às mudanças e aos desafios diários.

Corroborando com Valls (2007), é necessário reconhecer que a qualidade em unidades de informação indui planejamento estratégico, gerenciamento de recursos e outras atividades sistêmicas, a exemplo do próprio planejamento, do controle e da melhoria da qualidade. Entre os benefícios da implantação da gestão da qualidade em serviços de informação, Valls (2007, p. 77), afirma que a aplicação da abordagem sistêmica abrange a compreensão que:

as atividades setoriais passam a ser de conhecimento de toda a equipe, de maneira transparente e compreensível, facilitando o entendimento das inter-relações e corresponsabilidades, havendo a clara definição das funções e responsabilidades de cada membro da equipe, nas quais todos passam a ser diretamente responsáveis pelo sistema de gestão da qualidade; integração com as demais áreas da Instituição mantenedora; maior integração das equipes técnicas, de atendimento, administrativas, etc; monitoramento da qualidade de todos os produtos e serviços implantados, de forma sistêmica e objetiva.

Com base nestes pressupostos teóricos, inferimos que a elaboração do Plano de Contingência em unidades de informação deverá possivelmente requerer uma indissociabilidade e um equilíbrio entre a abordagem sistêmica, a abordagem contingencial, o contexto capacitante e o planejamento estratégico.

Antes de prosseguirmos com a discussão sobre Contingência, precisamos falar a respeito de estratégia. Não faremos um roteiro pela selva do planejamento estratégico, conforme Mintzberg, Ahlstrand e Lampel (2000) já o fizeram em livro, pois não teríamos espaço ou pretensão para tal em um artigo. O que pretendemos é agregar um ponto de vista que consideramos essencial para a reflexão que estamos tecendo.

Consideramos necessário que os bibliotecários que se veem diante da necessidade de elaborar um Plano de Contingência, possam antes de qualquer passo, compreender vantagens e desvantagens de se adotar uma estratégia para tal. Mintzberg, Ahlstrand e Lampel (2000), assinalam que para cada vantagem associada à estratégia, há uma desvantagem. Os autores afirmam que a estratégia fixa a direção, focaliza o esforço, define 
a organização e provê consistência (Quadro 1). Com base nessas quatro perspectivas da estratégia, elaboramos um quadro que sintetiza a visão dos autores e nos possibilita inferir e refletir sobre vantagens, desvantagens e recomendações que sirvam para o Plano de Contingência em biblioteca multinível.

Analisando criticamente cada um desses quatros pontos, pretendemos destacar que a nossa reflexão sobre a teoria da contingência no contexto capacitante da biblioteca multinível consiste em uma visão estratégica sobre como os bibliotecários que atuam nesse contexto devem pensar e agir para a formulação, execução e avaliação dos Planos de Contingência. Trata-se de estabelecer um referencial teórico para a prática bibliotecária, uma diretriz que inspire o processo criativo para a ação, e de lançar mão de uma estratégia para obter rentabilidade.

Quadro 1 - Visão sobre a estratégia: vantagens, desvantagens e recomendações

\begin{tabular}{|c|c|c|c|}
\hline $\begin{array}{l}\text { Visão sobre a } \\
\text { estratégia }\end{array}$ & Vantagem & Desvantagem & Recomendação \\
\hline Fixa a direção & $\begin{array}{c}\text { Mapear o curso da } \\
\text { organização para } \\
\text { garantir } \\
\text { coerênciaemsuasações. }\end{array}$ & $\begin{array}{l}\text { Ocultar perigoem } \\
\text { potencial emum } \\
\text { ambiente } \\
\text { desconhecido. }\end{array}$ & $\begin{array}{l}\text { Movimentar-se com } \\
\text { cautela para mudar } \\
\text { oportunamente. }\end{array}$ \\
\hline Focaliza o esforço & $\begin{array}{l}\text { Coordenação das } \\
\text { atividades. }\end{array}$ & $\begin{array}{l}\text { Excesso de } \\
\text { focalização. }\end{array}$ & $\begin{array}{c}\text { Tentar mantervisão } \\
\text { periférica para abrir } \\
\text { outraspossibilidades. }\end{array}$ \\
\hline Define a organização & $\begin{array}{c}\text { Propicia } \\
\text { autoconhecimento sobre } \\
\text { o que a organização faz } \\
\text { e } \\
\text { discernimentoemre lação } \\
\text { as outras. }\end{array}$ & $\begin{array}{c}\text { Excesso de } \\
\text { simplicidade pode } \\
\text { levar à criação de } \\
\text { estereótipo, perdendo- } \\
\text { se a rica complexidade } \\
\text { do sistema. }\end{array}$ & $\begin{array}{c}\text { Não definir a } \\
\text { organizaçãocomexcesso } \\
\text { de exatidão, mas } \\
\text { simcomabrangência e } \\
\text { criticidade. }\end{array}$ \\
\hline Provêconsistência & $\begin{array}{l}\text { Reduzambiguidade, } \\
\text { provê a ordem, facilita a } \\
\text { ação. }\end{array}$ & $\begin{array}{l}\text { Pode gerarinformação } \\
\text { falsa oudistorção da } \\
\text { realidade. }\end{array}$ & $\begin{array}{l}\text { Compreender que } \\
\text { estratégia é } \\
\text { umarepresentação } \\
\text { mental da realidade. }\end{array}$ \\
\hline
\end{tabular}

Fonte: Adaptado de Mintzberg, Ahlstrand e Lampel (2000).

Estrategicamente, em primeiro lugar, a biblioteca multinível ao elaborar o Plano de Contingência deverá fixar a direção(identificar qual é a visão da organização, o que ela pretende alcançar no futuro), levando em consideração o curso da organização em que ela está inserida, para 
garantir coerência em suas ações. Contudo, deve movimentar-se prudentemente para mudar oportunamente, driblando o perigo em potencial que é o ambiente desconhecido. Isto se constitui em uma forma de não colocar em risco a estratégia adotada. Neste sentido, o bibliotecário deve considerar que em 2018, não somente as universidades, mas também os institutos federais de educação e diversas outras instituições de ensino que ofertam cursos na modalidade superior, foram surpreendidas com muitas mudanças no processo de avaliação dos cursos superiores, que é conduzido pelo Instituto Nacional de Estudos e Pesquisas Educacionais Anísio Teixeira (INEP), do Ministério da Educação (MEC).

A partir de março de 2018, os instrumentos de avaliação para monitorar a qualidadedos cursos de graduação presenciais e a distância sofreram alterações significativas. Entre as principais, podemos destacar a separação dos instrumentos de autorização e reconhecimento, deixando claras as diferenças entre o previsto e o implantado. Além disso, os indicadores quantitativos foram reduzidos e a análise passou a ser mais qualitativa. Essas mudanças, indubitavelmente, tornaram os instrumentos mais minuciosos e subjetivos.

Para fins de esclarecimento, de acordo com o INEP (2017), o reconhecimento de curso é condição necessária para a validade nacional do diploma e deve ser solicitado pela instituição de ensino superior quando o curso de graduação tiver completado $50 \%$ de sua carga horária. Enquanto a renovação do reconhecimento é solicitada ao final de cada ciclo avaliativo do Sistema Nacional de Avaliação da Educação Superior (SINAES). O instrumento que trata desses processos é, portanto, de suma importância para que a instituição de ensino e a biblioteca obtenham conceito máximo de qualidade.

Com foco na análise qualitativa, verifica-se que os indicadores relacionados à biblioteca foram reduzidos de três para dois, e se tornaram muito mais robustos e qualitativos, com muitos mais elementos informativos e exigências. Com esse aprimoramento, o instrumento de reconhecimento/renovação de reconhecimento trouxe algumas novidades para a prática bibliotecária. Dentre elas, que "O acervo é gerenciado de modo a atualizar a quantidade de exemplares e/ou assinaturas de acesso mais demandadas, sendo adotado Plano de Contingência para a garantia do acesso e do serviço" (INEP, 2017, p. 32). Esse requisito está presente em ambos os indicadores relacionados à biblioteca, a saber: Indicador 3.6 Bibliografia básica por Unidade Curricular e 3.7 Bibliografia complementar por Unidade Curricular. Outro aspecto notável que verificamos é que essa exigência é requisito exclusivo para obtenção do conceito 5 , que é o conceito máximo que pode ser atribuído a cada indicador no processo avaliativo. O Plano de Contingência não é solicitado para obtenção dos 
demais conceitos (de 1 a 4). Torna-se, portanto, impreterível que a biblioteca elabore seu Plano de Contingência, afinal toda instituição de ensino superior almeja o conceito máximo, e exige que todos os membros da organização colaborem para tal, incluindo a unidade de informação.

Em todo o Brasil, nas listas de discussões por e-mail, por rede social e em grupos de bibliotecários presentes nas diversas instituições de ensino pelo país, uma dentre várias questões se destacou, a saber: 0 que é Plano de Contingência?; revelando que muitas bibliotecas não possuem tal documento, afinal seus bibliotecários ainda não estão imbuídos da compreensão teórica necessária para sua elaboração. Essa é uma realidade compreensível, se levarmos em consideração que até então não haviam instrumentos legais exigindo a presença ou explicitando a importância de Plano de Contingência neste tipo de ambiente. Nem mesmo o campo científico vinha publicando a respeito desta temática.

Percebeu-se a realização de alguns cursos por iniciativa de bibliotecários pesquisadores e professores deste então, seja por iniciativa própria destes profissionais ou das instituições em que atuam, a fim de buscar a adequação aos indicadores. Verificou-se, que a literatura científica do campo da Biblioteconomia e da Ciência da Informação, nos últimos anos, não contemplou essa temática. A carência de referencial teórico é facilmente perceptível na busca pelos principais periódicos científicos da área e por meio das bases de dados de maior reputação, a exemplo de Brapci, SciELO e Portal de Periódicos Capes.

Os novos instrumentos começaram a vigorar em março de 2018, e em maio do mesmo ano a Coordenação de Avaliação in loco, da Diretoria de Avaliação da Educação Superior (DAES) do INEP, lançou a primeira edição do Glossário dos Instrumentos de Avaliação Externa com o objetivo de que ele fosse um instrumento legítimo e bem-sucedido para dirimir as dúvidas oriundas das mudanças realizadas. Devido as contribuições, críticas e relatos de várias pessoas que trabalham diretamente com a educação superior, e possivelmente de bibliotecários, o INEP se esforçou para manter a atualização periódica do Glossário, e em apenas dois meses após o lançamento da primeira edição, em julho de 2018, foi lançada a $2^{a}$ edição, com a inclusão de mais 22 (vinte e dois) novos verbetes, dentre eles Contingência e Plano de Contingência.

O INEP cita o Dicionário Michaelis para definir Contingênciacomo sendo uma "dúvida quanto à possibilidade de uma coisa acontecer ou não"; ou um "fato cuja ocorrência é possível, porém incerta; eventualidade, imprevisto" (INEP, 2018, p. 68). Sobre o conceito e a função do Plano de Contingência, o $\operatorname{INEP}(2018$, p. 68) se posiciona da seguinte forma: 
De acordo com a Enciclopédia Knoow.net, Plano de Contingência é um tipo de plano preventivo, preditivo e reativo. Apresenta uma estrutura estratégica e operativa que ajudará a controlar uma situação de emergência e a minimizar as suas consequências negativas. O plano de contingência propõe uma série de procedimentos alternativos ao funcionamento normal de uma organização, sempre que alguma de suas funções usuais se vê prejudicada por uma contingência interna ou externa. Essa classe de plano procura, portanto, garantir a continuidade do funcionamento da organização face a quaisquer eventualidades, sejam estas materiais ou pessoais. Um plano de contingência inclui quatro etapas básicas: a avaliação, a planificação, as provas de viabilidade e a execução.

Observa-se que um Plano de Contingência é um elemento estratégico e operacional de qualquer organização, e que sua estrutura obedece a esse propósito. Não está restrito a questões específicas, sendo amplo e aplicável a diversos contextos organizacionais, inclusive em bibliotecas. Fica evidente que a intenção do INEP/MEC com a inclusão desse documento no indicador de qualidade do processo de avaliação dos cursos superiores, foi de garantir a continuidade do acesso à informação e aos recursos informacionais oferecidos nos diversos serviços da biblioteca, frente a qualquer evento inesperado que venha a impedir o acesso e uso convencional. De fato, constitui-se em um significativo passo em direção a garantia da qualidade dos serviços informacionais, tendo em vista que antes desse instrumento, o indicador de qualidade estava restrito a aspectos quantitativos, a exemplo do quantitativo de títulos e exemplares do acervo bibliográfico.

A fonte citada pelo INEP/MEC, a Knoow.net, consiste em uma enciclopédia temática de acesso livre e gratuito, desenvolvida sob a responsabilidade de Paulo Nunes, Economista pela Universidade Nova de Lisboa, professor universitário nas áreas de Economia e Gestão, gestor e consultor de empresas. Outros especialistas contribuem para sua construção, a exemplo da economista Catarina Martins, autora da página da enciclopédia que versa sobre Plano de Contingência. No texto verificamos que a referência utilizada para elaboração do conteúdo é de um livro de António Gomes Mota, intitulado "Finanças da Empresa: da teoria à prática", 5a edição, publicado em 2012, pela EdiçõesSílabo, em Lisboa, Portugal. Esse fato não causa estranheza, pois não é de hoje que princípios da Economia são aplicados ao contexto das unidades de informação no campo da Biblioteconomia. Um exemplo bastante 
conhecido na gestão de coleções em bibliotecas é o princípio $80 / 20^{1}$, em que Trueswell (1969) verificou que $80 \%$ das demandas dos usuários são atendidas por $20 \%$ do acervo. De acordo com Lima (1986, p. 129) "esta regra $80 / 20$ é importante quando se considera que é impraticável desenvolver uma coleção que reúna todos os itens publicados em uma área do conhecimento".

Verificou-se, também, que a enciclopédia tem mais informações que podem auxiliar a compreensão do Plano de Contingência em biblioteca. Martins (2017), para além do que o INEP/MEC apresenta no Glossário, menciona na Enciclopédia Knoow. net que um Plano de Contingência também deve estabelecer objetivos estratégicos e um plano de ação para cumprir com as suas metas. Exemplifica que na informática, um plano de contingência pode ser um programa alternativo para que uma empresa possa se recuperar de um desastre informático e reestabelecer as suas operações com rapidez. No caso da biblioteca multinível, podemos citar como Plano de Contingência diversos softwares de automação e muitos recursos informacionais impressos e digitais que possibilitem ou supram os meios convencionais de acesso e uso à informação. Por exemplo, para acessar um Trabalho de Conclusão de Curso, o Plano de Contingência pode prever que a biblioteca tenha a versão impressa no acervo e a versão digital em um repositório digital. Assim como, na ausência de conteúdo em livros impressos no acervo, a biblioteca deve dispor de meios para acesso ao conteúdo em bases de dados online. O Plano de Contingência, neste caso, será tão abrangente quanto for a complexidade dos produtos e serviços informacionais oferecidos na biblioteca, o que será percebido a partir do tipo e porte da biblioteca, do quantitativo e do perfil de usuários da informação que dela se utilizam, dos cursos (médio, técnico, superior, entre outros) oferecidos pela instituição mantenedora, e de todo o conjunto de atribuições que a ela são cabíveis no tocante a suprir as necessidades informacionais, oportunizar a produção de conhecimentos e apoiar o ensino, a pesquisa, a extensão, entre outras.

As estratégias podem ser vitais para as organizações tanto por sua ausência, quanto por sua presença. No entanto, nesse contexto em específico, é evidente que a estratégia é indissociável da contingência. Conforme dito no quarto ponto do Quadro 1, a estratégia provê consistência. De acordo com Mintzberg, Ahlstrand e Lampel (2000, p. 22), "uma estratégia é como uma teoria: uma estrutura cognitiva para simplificar e explicar o mundo e com isso facilitar a ação". O que não

${ }^{1}$ O Princípio de Pareto, sugerido por Joseph MosesJuran, diz que $80 \%$ das consequências de um fenômeno são originadas por $20 \%$ das causas, sendo aplicável a diversas outras relações de causa e efeito. 
podemos esquecer, e os autores nos fundamentam nesse argumento, é que:

toda estratégia, como toda teoria, é uma simplificação que necessariamente distorce a realidade. Estratégias e teorias não são realidades; apenas representações (ou abstrações) da realidade na mente das pessoas. Ninguém jamais tocou ou viu uma estratégia. Isso significa que cada estratégia pode ter um efeito de informação falsa ou distorção. Esse é o preço de se ter uma estratégia.

O Plano de Contingência na biblioteca multinível é uma estratégia para driblar o caos, para superar um imprevisto, e para garantir a exequibilidade de tarefas, não interrompendo o seu funcionamento. 0 risco de estabelecer uma estratégia errônea sempre acompanhará qualquer Plano, seja de Contingência, de Marketing, ou de qualquer outra atividade administrativa na unidade de informação. Porém, o risco de fracasso e de perdas é muito maior quando a biblioteca não dispõe de um Plano, qualquer que ele seja, inclusive de Contingência. Fracasso para a instituição e perda, principalmente, para os usuários da informação que ficarão desprovidos de alternativas. Nos dias atuais, a ausência do Plano de Contingência também denota a perda do conceito 5 no indicador de qualidade dos cursos superiores.

Martins (2017, p.1), discorrendo sobre as razões para as empresas adotarem planos de contingência, afirma que:

O plano de contingência deve permitir que a empresa se mantenha em funcionamento durante o choque externo até que este seja totalmente ultrapassado. Para que a sua execução seja eficaz, o plano de contingência deve ser elaborado de forma a permitir que a empresa atue rapidamente e especificamente nos problemas que está a resolver. Por exemplo, um plano de contingência pode consistir na manutenção de uma reserva oculta para fazer face a guerras de preços ou a falha do lançamento de um novo produto no mercado; pode ser uma equipa de gestão de emergência para substituir a equipa de gestão sénior caso esta se encontre incapacitada ou várias outras situações.

Com base no que foi discutido até o momento e nos outros dois pontos destacados no Quadro 1, afirmamos que sem a estratégia, as pessoas teriam muito mais dificuldade para elaborar, executar e avaliar um Plano de Contingência, pois tal atividade demanda coordenação de atividades e focalização dos esforços, para que não se perca a direção. A estratégia define a organização, mas é preciso que as pessoas além de 
conhecerem a estrutura e o funcionamento da mesma, e de distingui-la das outras, a percebam com abrangência, sem limitar seu espaço de atuação, e com criticidade, para não a estereotipar ao ponto de não compreender sua complexidade e seu potencial.

Neste sentido, acreditamos que um contexto favorável a criação de conhecimento é um fator importante para a devida resolução das demandas emergenciais, a começar pela elaboração e implementação do Plano, que deve ser um processo coletivo, participativo, em constante construção e atualização. É necessário, portanto, a compreensão do contexto capacitante da biblioteca multinível para seguirmos adiante.

\section{O contexto capacitante da biblioteca multinível}

No Brasil, a biblioteca multinível está presente em 38 Institutos Federais de Educação, Ciência e Tecnologia, presente em todas as 27 unidades federativas do território nacional. Esses Institutos foram criados pela Lei $n^{\circ}$ 11.982, de 29 de dezembro de 2008, que instituiu a reestruturação da Rede Federal de Educação Profissional, Científica e Tecnológica. Denominamos reestruturação, pois essa Rede Federal já existe há 110 anos no Brasil, oriunda das Escolas de Aprendizes e Artífices.

Desde então, 31 Centros Federais de Educação Tecnológica (CEFETs), 75 Unidades Descentralizadas de Ensino (UNEDs), 39 Escolas Agrotécnicas, 7 Escolas Técnicas Federais e 8 Escolas Técnicas vinculadas a Universidades deixaram de existir para compor 0 que hoje denominamos de Institutos Federais de Educação, Ciência e Tecnologia. Diferentemente das Universidades, essas instituições de ensino possibilitam o acesso à educação profissional e tecnológica por meio da oferta de cursos em diversos níveis de ensino, a saber: Profissionalizante, Educação de Jovens e Adultos, Médio, Técnico, Superior e Pós-Graduação. Nestes níveis, incluem-se as mais diversas modalidades, a saber: Médio Integrado ao Técnico, Técnico Subsequente, Superior (Tecnológico, Bacharelado e Licenciatura), Pós-Graduação (Lato e Stricto Sensu), além de cursos profissionalizantes de Formação Inicial e Continuada (FIC), o Programa de Educação de Jovens e Adultos (PROEJA), e outras práticas de educação profissional e tecnológica em programas e projetos governamentais orientados para a geração de emprego e acesso ao mercado de trabalho, a exemplo do Programa de Acesso ao Ensino Técnico e ao Emprego (PRONATEC) e do Programa Mulheres Mil. Este universo diferenciado e abrangente de níveis de ensino apresenta um desafio complexo às bibliotecas, que nos últimos anos têm repensado sua própria identidade e suas ações e práticas no contexto dessa nova configuração das instituições federais de ensino profissional e tecnológico. 
Uma nova realidade emerge, diferente da que existe em biblioteca escolar e universitária.

Moutinho (2014) propôs, pela primeira vez na literatura científica, a adoção da terminologia biblioteca multinível para as bibliotecas dessa natureza. Na condição de bibliotecária de um Instituto Federal e de pesquisadora Mestre em Educação, durante sua pesquisa sobre práticas de leitura na cultura digital de alunos do ensino técnico integrado, a autora identificou que esse tipo de biblioteca é percebido como uma organização que atende às necessidades de um público de diferentes níveis de processos formativos (nível médio, técnico e superior) e, consequentemente, diferentes níveis de necessidade e competência informacional.

Almeida (2015), a partir de uma pesquisa realizada em nível de Mestrado, com enfoque na biblioteca aprendente e no desenvolvimento de competência em informação, aprofunda essa perspectiva teórica e compreende que biblioteca multinível é toda unidade de informação que quanto à finalidade atende aos usuários de diversos níveis de ensino. Considerando esta perspectiva mais completa e abrangente da complexidade que diferencia $s$ identidade dessa biblioteca das demais (escolares, universitárias e especializadas), adota-se a terminologia biblioteca multinível desde então para classificar a identidade das bibliotecas dos Institutos Federais, e defende-se que deve ser reconhecida como um novo tipo de biblioteca quanto a finalidade, aos serviços oferecidos e as práticas realizadas.

Almeida (2015) afirma que quanto a finalidade, a biblioteca multinível atende às necessidades de estudo, consulta e pesquisa de professores, servidores técnico-administrativos e alunos em nível profissionalizante, médio, técnico, superior de graduação e pós-graduação (lato e stricto sensu). Segundo a organização das coleções, assemelhamse às universitárias, podendo ser centralizadas ou descentralizadas. São, por exemplo, as bibliotecas das instituições da Rede Federal de Educação Profissional, Científica e Tecnológica no Brasil².

A análise do conceito, das características e da complexidade do contexto de atuação da biblioteca multinível expostos acima, oportunizou o surgimento de um questionamento, a saber: Como desenvolver as condições necessárias para a criação do conhecimento neste ambiente? Em específico, neste momento, nos dedicamos a pensar sobre a aplicação teórica da abordagem contingencial no contexto capacitante da biblioteca

\footnotetext{
${ }^{2}$ No contexto do sistema federal de ensino no Brasil,aRede Federal de Educação Profissional, Científica e Tecnológica é constituída em sua maioria por 38 Institutos Federais de Educação, Ciência e Tecnologia (IFs), e em minoria por 2 Centros Federais de Educação Tecnológica (CEFETs), 25 escolas técnicas vinculadas às Universidades, o Colégio Pedro II e uma Universidade Tecnológica.
} 
multinível e quais as melhores condições para elaborar um Plano de Contingência.

Krogh, Ichijo e Nonaka (2001) afirmam que um contexto capacitante não é necessariamente um ambiente físico, podendo vir a ser uma rede de interações, determinada pela solicitude e pela confiança dos participantes, para que ocorra o desenvolvimento das condições necessárias à criação do conhecimento. O próprio processo de produção de um Plano de Contingência constitui um ato coletivo de criação de conhecimento. Um ato coletivo, que demandará da organização a formação de uma microcomunidade de conhecimento para sua adequada elaboração, afinal, a contingência em relação ao acesso e uso da informação e dos recursos informacionais demandará esforços de uma equipe multidisciplinar na biblioteca multinível.

Em se tratando de atividades realizadas em equipe, corroborando com Krogh, Ichijo e Nonaka (2001, p. 61), não podemos deixar de destacar que "a criação de conhecimento exige muito dos relacionamentos na organização". No campo da Ciência da Informação, em estudo recente sobre a competência em informação como instrumento de qualidade na área de negócios, Smith, Fadel e Pinto (2015) constataram a necessidade de atitudes embasadas em competência em informação para ampliar a capacidade dos gestores e demais colaboradores de colocarem em prática de maneira integrada as habilidades do fazer, as experiências vivenciadas e os saberes específicos. Dessa forma, as autoras afirmam que as habilidades conjuntas subsidiariam a solução de problemas, o enfrentamento e a adaptação às situações adversas, e consequentemente a promoção da gestão integral da organização.

Nesta perspectiva, ressaltamos que da mesma forma que o desenvolvimento de competência em informação é percebido por Almeida e Freire (2018) e por Veiga, Pimenta e Silva (2018) como uma atividade baseada em projeto na biblioteca multinível, assim também recomendamos que seja o processo de produção do Plano de Contingência. Este processo, demanda que compreendamos o contexto capacitante da biblioteca multinível como um contexto de criação de conhecimento que é determinado pela solicitude. Afinal, conforme mencionado por Krogh, Ichijo e Nonaka (2001, p. 72), "é evidente que a criação de conhecimento pode assumir diferentes rumos, dependendo da solicitude", se a mesma for alta ou baixa (Quadro 2).

Quadro 2 - Criação de Conhecimento quando a Solicitude é Alta ou Baixa

\begin{tabular}{|c|c|c|}
\hline & Conhecimento Individual & Conhecimento Social \\
\hline Baixa & CAPTURA & TRANSAÇÃO \\
Solicitude & Cada um por si & Troca de documentos ou de \\
\hline
\end{tabular}




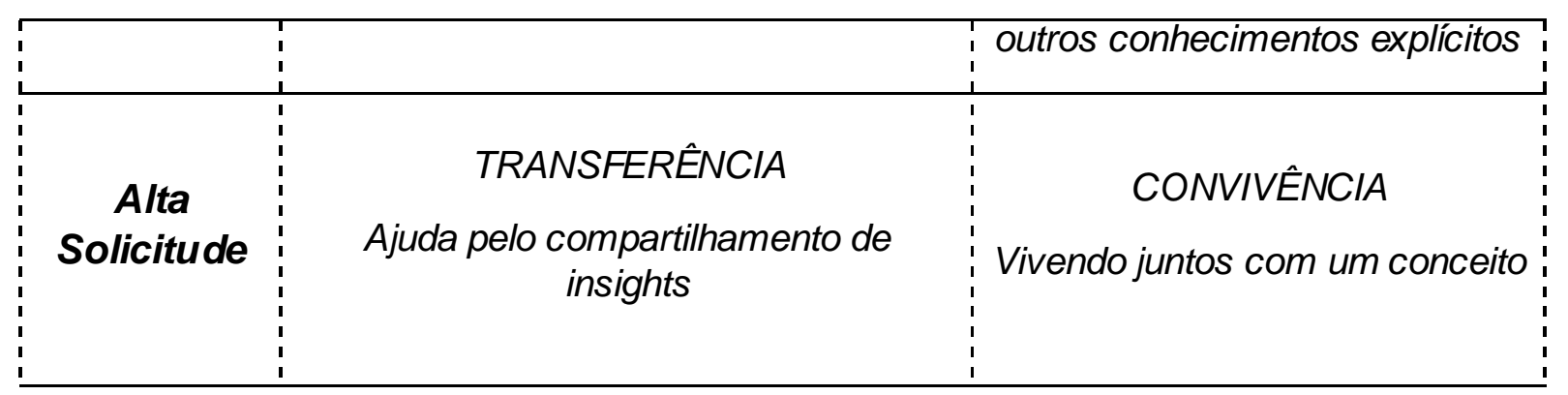

Fonte: Krogh, Ichijo e Nonaka (2001).

Krogh, Ichijo e Nonaka (2001, p. 72) explicam que:

Em condições de baixa solicitude, a criação de conhecimento individual se baseia no processo de captura, e boa parte da criação de conhecimento social ocorre por meio da transação. No entanto, quando a solicitude é alta, os processos de criação de conhecimento mudam para refletir os relacionamentos mais fortes. As pessoas criam conhecimento individual mediante transferência de insights e os grupos geram o conhecimento social por meio do que chamamos de convivência.

O contexto capacitante da biblioteca multinível, para a elaboração, execução e avaliação do Plano de Contingência, deverá ter alta solicitude entre a equipe multidisciplinar que envolve bibliotecários, auxiliares de biblioteca, pedagogos, analistas de sistemas e alta gestão. Além de incluir outros profissionais que possam ter relevância e agregar valor ao conhecimento que se produz em uma situação como essa, que exigirá múltiplos olhares e diversas competências, em especial, competência em informação para o atendimento das demandas emergenciais em relação ao acesso e uso da informação.

Em um ambiente organizacional em que os sujeitos compreendem o conceito de biblioteca multinível e a importância e abrangência de sua atuação, e convivem em um ambiente que estimula o compartilhamento de insights, é possível que tenhamos grandes chances de criar um Plano de Contingência eficaz e rentável, que atenda não somente uma exigência de um instrumento de avaliação, mas sobretudo, possa garantir o acesso e o serviço de informação, controlando, portanto, uma situação de emergência e minimizando as suas consequências negativas para os usuários da informação na biblioteca multinível. No planejamento estratégico da unidade de informação, a solicitude é totalmente indispensável, seja baixa ou alta, pois o que realmente interessa é o conhecimento social disponibilizado.

\section{Conclusão}


Analogamente à abordagem sistêmica, a Teoria da Contingência nos permite compreender a organização como um sistema aberto, em que as variáveis externas do ambiente (público alvo, concorrência, fornecedores, entre outros) exercem influência nas variáveis internas da biblioteca (tecnologia, estrutura, estratégia e porte organizacional) de forma interdependente (ESPEJO, 2008). A relação da abordagem contingencial pela biblioteca multinível perpassa a necessidade de um ambiente favorável à criação de conhecimento, cujo contexto capacitante é fundamental.

Uma interseção foi iniciada a partir do presente trabalho, demonstrando teoricamente a viabilidade da abordagem contingencial no contexto capacitante da biblioteca multinível, baseado principalmente na capacidade de criar conhecimento e desenvolver competência em informação em um ambiente com alta solicitude.

Conclui-se, portanto, que os postulados teóricos abordados requerem contexto capacitante, que oportunize não somente a criação de conhecimento, mas o desenvolvimento de competência em informação necessária para a elaboração, execução e avaliação do Plano de Contingência.

Para o avanço dessa compreensão, recomenda-se que incursões sejam realizadas a fim de agregar pontos de vista diversificados, em especial sobre as quatro etapas básicas do Plano de Contingência segundo preconizado pelo INEP/MEC: a avaliação, a planificação, as provas de viabilidade e a execução. Ainda não está claro se o Plano de Contingência em bibliotecas deverá abranger provas de viabilidade técnica, econômica ou ambas. Nem foram produzidas e experimentadas formas de provar qualquer viabilidade frente aos riscos que existem em uma biblioteca. Recomenda-se, ainda, o investimento em estudo futuro sobre o efeito das dimensões da solicitude (confiança mútua, empatia ativa, acesso à ajuda, leniência nos julgamentos e coragem) no contexto capacitante da biblioteca multinível frente ao desenvolvimento de qualquer Plano, seja de Contingência, de Marketing, de Automação, ou outros necessários ao melhor funcionamento da unidade de informação.

\section{Referências}

ALMEIDA, Jobson Louis Santos de. A biblioteca como organização aprendente: o desenvolvimento de competências em informação no Instituto Federal de Educação, Ciência e Tecnologia da Paraíba. 2015. Dissertação (Mestrado em Gestão nas Organizações Aprendentes) Programa de Pós-Graduação em Gestão nas Organizações Aprendentes, Universidade Federal da Paraíba, João Pessoa, 2015. Disponível em: https://repositorio.ufpb.br/jspui/handle/tede/7671. Acesso em: 03 nov. 2018. 
ALMEIDA, Jobson Louis Santos de; FREIRE, Gustavo Henrique de Araújo. Projeto educativo para competências em informação: bases teóricas para a pesquisa-ação em uma biblioteca multinível. Revista Encontros Bibli, Florianópolis, v. 23, n. 51, p. 123-137, 2018.Disponível em: https://periodicos.ufsc.br/index.php/eb/article/view/15182924.2018v23n51p123. Acesso em: 03 nov. 2018.

BEUREN, Ilse Maria; FIORENTIN, Marlene. Influência de fatores contingenciais nos atributos do sistema de contabilidade gerencial: um estudo em empresas têxteis do Estado do Rio Grande do Sul. Revista de Ciências da Administração, Florianópolis, v. 16, n. 38, p. 196-212, 2014.Disponível em: https://periodicos.ufsc.br/index.php/adm/article/view/21758077.2014v16n38p195. Acesso em: 22 nov. 2018.

CHIAVENATO, Idalberto. Introdução à teoria geral da administração. 9. ed. São Paulo: Manole, 2014.

ESPEJO, Márcia Maria dos Santos Bortolocci. Perfil dos atributos do sistema orçamentário sob a perspectiva contingencial: uma abordagem multivariada. 2008. $216 \mathrm{f}$. Tese (Doutorado em Controladoria e Contabilidade). Universidade de São Paulo, São Paulo, 2008. Disponívelem: https://www.teses.usp.br/teses/disponiveis/12/12136/tde-30062008141909/pt-br.php. Acesso em: 22 nov. 2018.

GARCÍA-REYES, Carmem Jorge. Gestión de unidades de información. In: VERGUEIRO, Waldomiro; MIRANDA, Angélica C. D. (orgs.). Administração de unidades de informação. Rio Grande: FURG, 2007.

INEP. Instrumento de avaliação de cursos de graduação presencial e a distância: reconhecimento/renovação de reconhecimento. Brasília:

INEP/MEC, 2017.Disponível em: http://inep.gov.br/instrumentos. Acesso em: 14jan. 2019.

INEP. Glossário dos instrumentos de avaliação externa. 2. ed. Brasília: INEP/MEC, 2018. Disponível em: http://inep.gov.br/web/guest/educacaosuperior/avaliacao-dos-cursos-de-graduacao/glossario. Acesso em: 14jan. 2019.

KROGH, Georg von; ICHIJO, Kazuo; NONAKA, Ikujiro. Facilitando a criação de conhecimento: reinventando a empresa com o poder da inovação contínua. Rio de Janeiro: Campus, 2001.

LIMA, Regina Célia Montenegro de. Bibliometria: análise quantitativa da literatura como instrumento de administração em sistema de informação. Ciência da Informação, Brasília, v. 15, n. 2, p. 127-133, 1986.Disponível 
em: http://revista.ibict.br/ciinf/article/view/233. Acesso em: 22 nov. 2018.

LONGO, Rose Mary Juliano. Gestão do conhecimento e unidades de informação. In: VERGUEIRO, Waldomiro; MIRANDA, Angélica C. D. (Orgs.). Administração de unidades de informação. Rio Grande: FURG, 2007.Disponível

em:http://www.repositorio.furg.br/bitstream/handle/1/7627/Vergueiro $\% 2$ C\%20W.\%20\%20e\%20Miranda\%2C\%20A.\%20C.\%20D..pdf? sequence $=1$. Acesso em: 22 nov. 2018.

MARTINS, Catarina. Plano de Contingência. In:ENCICLOPEDIA temática Knoow.net. 2017. Disponível em: http://knoow.net/cienceconempr/gestao/plano-de-contingencia/. Acesso em: 14 jan. 2019.

MINTZBERG, Henry; AHLSTRAND, Bruce; LAMPEL, Joseph. Safári de estratégia: um roteiro pela selva do planejamento estratégico. Porto Alegre: Bookman, 2000.

MOUTINO, Sônia Oliveira Matos. Práticas de leitura na cultura digital de alunos do ensino técnico integrado do IFPI - Campus Teresina Zona Sul. 2014. Dissertação (Mestrado em Educação) - Programa de Pós-Graduação em Educação, Universidade Vale do Rio dos Sinos, São Leopoldo, 2014.Disponível

em: http://www.repositorio.jesuita.org.br/handle/UNISINOS/3075. Acesso em: 02 set. 2018.

SMITH, Marinês Santana; FADEL, Barbara; PINTO, María. Competência em informação na área de negócios: proposta e perspectiva do Modelo Business InformationCompetencies (BIC). In: BELLUZZO, Regina Célia Baptista (Org.). Redes de conhecimento e competência em informação: interfaces da gestão, mediação e uso da informação. Rio de Janeiro: Interciência, 2015.

TRUESWELL, Richard W. User circulation satisfacticm versus size of holding at three academic libraries.College\&ResearchLibraries, v. 30, n. 3, p. 204-13, 1969.Disponível em:

https://crl.acrl.org/index.php/crl/article/view/12124/13570. Acesso em: 10dez. 2018.

VALLS, Valéria Martin. Qualidade em unidades de informação. In: VERGUEIRO, Waldomiro; MIRANDA, Angélica C. D. (Orgs.). Administração de unidades de informação. Rio Grande: FURG, 2007. Disponível em:http://www.repositorio.furg.br/bitstream/handle/1/7627/Vergueiro $\% 2$ C\%20W.\%20\%20e\%20Miranda\%2C\%20A.\%20C.\%20D..pdf? sequence=1. Acesso em: 22 nov. 2018. 
VEIGA, Miriã Santana; PIMENTA, Jussara Santos; SILVA, Luciana Semeão. O desafio educacional dos bibliotecários nas bibliotecas multiníveis da Rede Federal de Educação Profissional, Científica e Tecnológica. Biblionline, João Pessoa, v. 14, n. 4, p. 49-64, 2018. Disponível em: https://periodicos.ufpb.br/ojs2/index.php/biblio/article/view/42957. Acessoem: 10dez. 2018. 